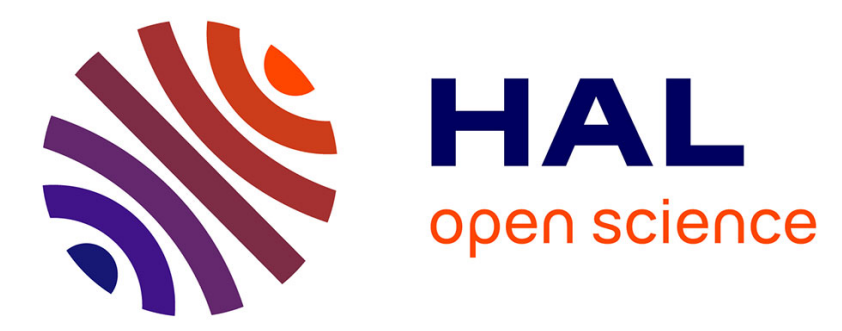

\title{
A numerical study of the influence from pre-existing cracks on granite rock fragmentation at percussive drilling
}

Mahdi Saadati, Pascal Forquin, Kenneth Weddfelt, Per-Lennart Larsson, François Hild

\section{To cite this version:}

Mahdi Saadati, Pascal Forquin, Kenneth Weddfelt, Per-Lennart Larsson, François Hild. A numerical study of the influence from pre-existing cracks on granite rock fragmentation at percussive drilling. International Journal for Numerical and Analytical Methods in Geomechanics, 2015, 39 (5), pp.558570. 10.1002/nag.2331. hal-01710049

\section{HAL Id: hal-01710049 \\ https://hal.science/hal-01710049}

Submitted on 5 Nov 2019

HAL is a multi-disciplinary open access archive for the deposit and dissemination of scientific research documents, whether they are published or not. The documents may come from teaching and research institutions in France or abroad, or from public or private research centers.
L'archive ouverte pluridisciplinaire HAL, est destinée au dépôt et à la diffusion de documents scientifiques de niveau recherche, publiés ou non, émanant des établissements d'enseignement et de recherche français ou étrangers, des laboratoires publics ou privés. 


\title{
A numerical study of the influence from pre-existing cracks on granite rock fragmentation at percussive drilling
}

\author{
Mahdi Saadati ${ }^{1,2}$, Pascal Forquin ${ }^{3}$, Kenneth Weddfelt ${ }^{2}$, Per-Lennart Larsson ${ }^{1}$ \\ and Francois $\mathrm{Hild}^{4}$ \\ ${ }^{1}$ Department of Solid Mechanics, KTH Royal Institute of Technology, Stockholm, Sweden \\ ${ }^{2}$ Atlas Copco, Örebro, Sweden \\ ${ }^{3} 3 S R$ Lab., Grenoble-Alpes University, Grenoble, France \\ ${ }^{4}$ LMT Cachan, ENS Cachan/CNRS/PRES UniverSud Paris, Cachan, France
}

\begin{abstract}
SUMMARY
The aim of this study is to investigate the effect of pre-existing, or structural, cracks on dynamic fragmentation of granite. Because of the complex behavior of rock materials, a continuum approach is employed relying upon a plasticity model with yield surface locus as a quadratic function of the mean pressure in the principal stress space coupled with an anisotropic damage model. In particular, Bohus granite rock is investigated, and the material parameters are chosen based on previous experiments. The equation of motion is discretized using a finite element approach, and the explicit time integration method is employed. The pre-existing cracks are introduced in the model by considering sets of elements with negligible tensile strength that leads to their immediate failure when loaded in tension even though they still carry compressive loads as crack closure occurs because of compressive stresses. Previously performed edge-on impact tests are reconsidered here to validate the numerical model. Percussive drilling is simulated, and the influence of the presence of pre-existing cracks is studied. The results from the analysis with different crack lengths and orientations are compared in terms of penetration stiffness and fracture pattern. It is shown that pre-existing cracks in all investigated cases facilitate the drilling process. Copyright (C) 2014 John Wiley \& Sons, Ltd.
\end{abstract}

KEY WORDS: granite; percussive drilling; KST-DFH model; pre-existing cracks; fragmentation

\section{INTRODUCTION}

The fragmentation process in brittle materials as a result of dynamic loadings has been investigated quite frequently in the literature. Fragmentation occurs in a wide range of applications from blasting in open quarries, concrete structures exposed to impact loading to screen rupture of cell phones as a result of free fall. Percussive drilling, which is the application of interest in this investigation, includes stress waves and high-velocity indentation. This type of loading causes high local strain rates in the rock and makes the problem transient dynamic. The stress distribution in the drilled rock includes both compressive stresses, mainly beneath the indenter as a result of high hydrostatic pressures, and tensile stresses around the contact region in different directions. This leads to various types of cracks such as radial, median and side cracks [1]. It is well known that brittle materials such as rocks behave differently in compression and tension [2]. Therefore, the constitutive specification for such materials in these types of applications should account for this difference and should be able to distinguish between the two different stress sign-dependent responses. 
A considerable effort has been made by researchers during the past years to numerically model the tool-rock interaction and rock fracture response during the percussive drilling process. Among the numerical studies that are performed in 2D, the work of Liu [3] and Wang et al. [4] can be mentioned. Both of these studies are performed using in-house numerical codes and do not account for inelastic strains in the rock. Another example of 2D numerical modeling of percussive drilling is the work by Saksala [5,6] where a viscoplasticity consistency model and an isotropic damage description are coupled to take both the compressive and the tensile responses of the rock into account. The model has been improved recently to deal with 3D simulations [7]. Furthermore, Chiang et al. [8] also used a 3D finite element (FE) approach to model the rock fragmentation during the drilling process by using a linear Mohr envelope together with a tension cutoff plane. Among the studies using discontinuous mechanics approach, Thuro et al. [9] used a Particle Flow Code $\left(\mathrm{PFC}^{2 \mathrm{D}}\right)$ to investigate the crack pattern in drilling and its correlation with existing foliations.

A continuum approach was used by Forquin and Hild [10] to study the dynamic fragmentation in a wide range of brittle materials in general as a result of impact loadings. A plasticity model introduced by Krieg [11], Swenson and Taylor [12] is employed together with an anisotropic damage model developed by Denoual and Hild [13], Forquin and Hild [10] (here and in the sequel referred to as the KST-DFH model). This model was used to describe the fragmentation of two grades of limestone subjected to edge-on impact (EOI) tests [14] and the strength improvement and failure pattern of a microconcrete [15, 16] and a standard concrete [17] during spalling tests and EOI experiments. Saadati et al. [18] applied the KST-DFH model on granite and investigated the rock fragmentation process and the force-penetration response at percussive drilling. It was shown that the KST-DFH model is an appropriate tool for this purpose as it deals with both dynamic fragmentation as a result of tensile stress and also plasticity-like deformation in compression. This is very similar to the situation at percussive drilling as the impact of the piston induces stress waves into the rock and initiates mode I (tensile) cracks, while high compressive stresses prevail beneath the indenter and lead to the crushing of the rock. The KST-DFH model parameters for Bohus granite have been determined based on previously reported experimental results [19]. It was shown that pre-existing cracks in granite have a significant effect on its mechanical response and the fracture pattern [18]. For instance, EOI tests, that is, impact of an aluminum projectile onto a rock slab, were performed. The tests were numerically modeled, and the results were compared with the experimental data in order to validate the constitutive model. The results from the EOI tests on granite were not completely satisfactory (as expected), and the number of large cracks was rather small. This was explained by relating this phenomenon to the presence of pre-existing cracks in the specimens. Preliminary simulations with pre-existing cracks were performed, and a qualitative agreement between experiments and simulations was obtained [18].

In the present investigation, the effect of the presence of pre-existing cracks (also called structural cracks) in the material is studied in detail and the simulations are compared with the experimental observations. Pre-existing cracks with different lengths and orientations are introduced in the numerical model of EOI specimens, and their effect on the fracture pattern is studied. Furthermore, the numerical tool is used to explore the influence of pre-existing cracks on penetration stiffness (the slope of the force-penetration curve of a drill bit) and the fracture pattern in the rock at percussive drilling. These cracks may result from former impact of the drill bit or by means of other exotic methods such as microwave and laser that are used to facilitate the percussive drilling process. The drilling efficiency is compared for pre-existing cracks with different lengths and orientations. All the results reported here concern Bohus granite rock characterized in ref. [19].

\section{CONSTITUTIVE SPECIFICATION}

\subsection{KST-DFH constitutive model}

The fragmentation process in brittle materials exposed to dynamic loadings, with particular application to percussive drilling, is of most interest in this investigation. The stress state in the material beneath the drilling tool consists of both compressive and tensile stresses. This is also the case when the 
material is impacted by a projectile in which a compressive state occurs underneath the projectile while tensile stresses are created because of compressive wave reflection or particle velocities. It is well known, as already mentioned in the preceding texts, that brittle materials such as rocks behave differently in compression and tension. Therefore, the constitutive specification for these materials to account for such types of phenomena should include this difference and should be able to distinguish between the two different stress sign-dependent responses. For this reason and based on a previous investigation [18], the KST-DFH constitutive model is selected to deal with the fragmentation modeling in brittle materials as a result of dynamic loading.

The KST-DFH material model is composed of two separate parts in order to deal with both compressive and tensile responses of the material. A plasticity model (KST $[11,12])$ is employed to simulate the compressive behavior of geomaterials accounting for the effect of hydrostatic and deviatoric parts of the stress tensor. The locus of the yield surface, in the deviatoric part, is a quadratic function of the mean pressure in the principal stress space

$$
\sigma_{e q}=\sqrt{a_{0}+a_{1} P+a_{2} P^{2}}
$$

where $\sigma_{e q}$ is the equivalent (von Mises) stress, $P$ the hydrostatic stress and $a_{0}, a_{1}$ and $a_{2}$ are materialdependent coefficients. Furthermore, a piecewise linear equation of state, determined by the points $\left(\varepsilon_{\mathrm{v}}^{(i)}, P^{(\mathrm{i})}\right)$ in Table $\mathrm{I}$, is included in order to link the volumetric strain, $\varepsilon_{v}$, to the hydrostatic stress. By increasing the pressure, pore collapse occurs in the case of porous rocks, which is modeled by an irreversible volumetric strain. During the porosity breakage, the bulk modulus, $K$, decreases noticeably. When all pores are closed, the material exhibits a higher bulk modulus that corresponds to the compacted material. However, granite exhibits constant bulk modulus in a wide range of hydrostatic stress as it includes a very small amount of porosity [19].

The fragmentation process, because of the opening of cracks, is defined by using a damage model (DFH), which is explained in details in refs. [10] and [13]. The main idea is that defects with

Table I. Material parameters used in the KST-DFH material model.

\begin{tabular}{lc}
\hline Mechanical parameters & \\
\hline$E(\mathrm{GPa})$ & 52 \\
$v$ & 0.15 \\
$\rho\left(\mathrm{kg} / \mathrm{m}^{3}\right)$ & 2630 \\
DFH model parameters & \\
Weibull parameters & 23 \\
$m$ & 18.7 \\
$\sigma_{w}(\mathrm{MPa})$ & 195 \\
$Z_{e f f}\left(\mathrm{~mm}^{3}\right)$ & \\
Obscuration volume parameter & 3.74 \\
$S$ & 0.38 \\
$k$ & 4400 \\
$C(\mathrm{~m} / \mathrm{s})$ & \\
$\mathrm{KST}$ model parameters & 31.7 \\
Parameters for hydrostatic behavior & 0.028 \\
$K(\mathrm{GPa})$ & $0 ; 860$ \\
$\varepsilon_{\mathrm{v}}^{(\mathrm{i})}$ & \\
$P^{(\mathrm{i})}(\mathrm{MPa})$ & 23,500 \\
Parameters for deviatoric behavior & 465 \\
$a_{0}(\mathrm{MPa})$ & 1.51 \\
$a_{1}(\mathrm{MPa})$ & 1.5 \\
$a_{2}$ & 11 \\
Cohesive model parameter & 0.004 \\
$\alpha_{D}$ & 1 \\
$\sigma_{g}^{d}(\mathrm{MPa})$ & \\
$\varepsilon_{o}$ & \\
$n_{d}$ & \\
\hline
\end{tabular}


different sizes and orientations are randomly distributed within the brittle materials, and consequently, the failure stress is a random variable. Accordingly, a probabilistic approach may be employed to explain the material response to tensile loadings. The weakest link theory and Weibull model are adopted as a framework for the damage model [20, 21].

The fragmentation response is strain and stress rate-dependent. At low loading rate conditions, the fracture process is generally the consequence of the initiation and growth of a single crack. This single crack is created from the activation and propagation of the weakest defect in the material. Crack propagation is so fast that the other defects do not get the opportunity to be activated, as the loading rate is low, and the failure of the whole structure occurs because of this single crack. Using a Poisson point process framework, the weakest link assumption and a Weibull model, the failure probability $P_{F}$ is given by

$$
P_{F}=1-\exp \left[-Z_{e f f} \lambda_{t}\left(\sigma_{F}\right)\right]
$$

where $Z_{\text {eff }}$ is the effective volume [22] and $\lambda_{t}$ is the initiation density defined by

$$
\lambda_{t}\left(\sigma_{F}\right)=\lambda_{0}\left(\frac{\sigma_{F}}{S_{0}}\right)^{m}
$$

where $m$ is the Weibull modulus, $S_{0}^{m} / \lambda_{0}$ is the Weibull scale parameter, and $\sigma_{F}$ the maximum principal stress in the whole domain.

Under high strain rate conditions, several cracks are initiated and propagate from the initial defects leading to multiple fragmentations. In that case, while the weakest defect is activated and propagates, several other cracks are initiated during this time. As the loading rate is high, there is enough time for the stress to reach high levels and activate smaller defects. When a crack is propagating at a very high velocity (a portion of the stress wave velocity), it relaxes the stresses in its vicinity. The multiple fragmentation process with multiple cracks growing at the same time stops when the whole structure is covered by these relaxed stress regions. The interaction law between cracks already initiated and the critical defects of the material is given by the concept of probability of non-obscuration $P_{n o}[10,13]$. In the case of multiple fragmentations, the interaction between the horizon (the region around a crack where stresses are relaxed because of crack opening) and the boundary of the domain $\Omega$ is small, and if a uniform stress field is assumed, the obscuration probability $P_{o}$ is written as [13]

$$
P_{o}(T)=1-P_{n o}(T)=1-\exp \left(-\int_{0}^{T} \frac{d \lambda_{t}}{d t}[\sigma(t)] Z_{o}(T-t) d t\right)
$$

In Eqn (4), $Z_{o}$ is the obscured zone, $\sigma$ the local eigenstress component, $T$ the current time and $t$ the crack initiation time. The probability of obscuration is defined for each eigendirection $i$, and the change of $P_{o i}$ is expressed in differential form, in order to be employed in an FE code using Eqn (4), as

$$
\frac{d^{2}}{d t^{2}}\left(\frac{1}{1-P_{o i}} \frac{d P_{o i}}{d t}\right)=3 ! S\left(k C_{0}\right)^{3} \lambda_{t}\left[\sigma_{i}(t)\right] \text { when } \frac{d \sigma_{i}}{d t}>0 \text { and } \sigma_{i}>0
$$

where $\sigma_{i}$ is the local eigenstress component.

More recently, Erzar and Forquin [23] have investigated the post-peak tensile behavior of concrete by means of Monte Carlo calculations and tensile experiments performed on damaged but unbroken spalled samples. An improvement of the modeling was proposed based on the following statement. Despite the propagation of the unstable cracks in the specimen, there is still a cohesive stress in the vicinity of these triggered cracks that controls the whole softening behavior of the material. Therefore, a cohesive model is combined with the KST-DFH model to describe the cohesive stress in the obscured zone and the softening behavior of geomaterials in dynamic tension [23, 24]. In the cohesive model, an extra term is added to the macroscopic stress $\Sigma_{i}$ as

$$
\Sigma_{i}=\left(1-P_{o i}\right) \sigma_{i}+\left(P_{o i}\right)^{\alpha_{D}} \sigma_{c o h}(\varepsilon)=\left(1-D_{i}\right) \sigma_{i}
$$


where $\sigma_{c o h}$ is the residual strength in the obscuration zone

$$
\sigma_{c o h}=\sigma_{o}^{d} \exp \left(-\left(\frac{\varepsilon}{\varepsilon_{0}^{d}}\right)^{n_{d}}\right)
$$

$\alpha_{D}, \sigma_{o}^{d}, \varepsilon_{o}^{d}, n_{d}$ are material-dependent parameters and $D_{i}$ is the damage variable defined for each principal direction. The cohesive term can be seen as an extra contribution related to the fracture energy of the material. It enforces the final failure of an element to occur when the dissipated energy as a result of the damage process reaches the fracture energy of the material.

In the eigenstress frame, the compliance tensor is defined by

$$
\left[\begin{array}{c}
\varepsilon_{1} \\
\varepsilon_{2} \\
\varepsilon_{3}
\end{array}\right]=\frac{1}{E}\left[\begin{array}{ccc}
\frac{1}{1-D_{1}} & -v & -v \\
-v & \frac{1}{1-D_{2}} & -v \\
-v & -v & \frac{1}{1-D_{3}}
\end{array}\right]\left[\begin{array}{c}
\Sigma_{1} \\
\Sigma_{2} \\
\Sigma_{3}
\end{array}\right]
$$

where $\varepsilon_{1}, \varepsilon_{2}, \varepsilon_{3}$ are the principal strains, and $E$ and $v$ are Young's modulus and Poisson's ratio of the undamaged material. At the inception of damage growth, the principal damage frame coincides with the principal stress tensor frame and the eigendirections may change at each time step until the first damage variable $D_{1}$ reaches a threshold value of 0.2 . After that, the direction of $D_{1}$ is locked, and the other directions $D_{2}$ and $D_{3}$ follow the eigendirections with the constraint to be perpendicular to $D_{1}$. When the second damage variable reaches the threshold value, all the directions are locked.

In the numerical analysis discussed in the succeeding texts, the Bohus granite rock characterized in ref. [19] is considered. Explicit values of the material parameters are presented in Table I. In ref. [19], a large number of mechanical tests were performed in order to describe Bohus granite rock based on the KST-DFH constitutive model. For example, a large number of flexural tests were performed, and the tensile strength from these tests was collected in a Weibull plot where the slope of the resulting curve determined the Weibull modulus $m$.

\subsection{Effect of structural cracks}

When structural cracks, which are because of many different reasons such as specimen preparation, are present in the material, the response of the material changes considerably (refer to e.g. [19]). Therefore, a modification is needed in the modeling to account for the effect of these cracks on the material behavior. One possible approach, which is used in this work, is to keep the original KST-DFH model as a constitutive specification for the intact material, that is, without any structural cracks. The structural cracks are then introduced in the numerical model with the desired length and orientation that may differ in each single specimen. This approach is considered here assuming that the structural cracks are rather few and long compared with microcracks modeled by the KST-DFH model. It should be noted once again that the interaction law between existing cracks and the critical defects of the material is given by the concept of probability of non-obscuration $P_{n o}[10,13]$.

As reported previously in ref. [18], the equation of motion is discretized using the FE method and the explicit time integration scheme is employed. The numerical simulation is carried through with the KST-DFH material model implemented as a VUMAT subroutine in the Abaqus Explicit software [25] with the strain increments given as input whereas final stress tensor and state variables are computed as output variables. In the subroutine, the integration scheme is mainly composed of two steps. In the first one, a microscopic stress tensor is calculated considering the KST constitutive law alone. The level of pressure is calculated from the volumetric strain increment considering a piecewise linear relationship between the volumetric strain and the hydrostatic pressure. The microscopic deviatoric stress tensor is calculated considering the isotropic pressure-dependent yield stress criterion defined in Eqn (1). In the second step, the three eigenvalues of the microscopic stress tensor are computed. In case of positive microscopic eigenstresses, a damage variable is calculated 
according to Eqn (5) and the macroscopic stress is derived (refer to Eqn (6). Finally, the macroscopic stress tensor is written in the initial basis.

The structural cracks are introduced in the FE model by selecting different sets of elements and allocating different material properties to them. The tensile strength is negligible in these elements that lead to their immediate failure, corresponding to a damage value being equal to one, as a result of tensile loading. The propagation of $3 \mathrm{D}$ cracks is simulated by recording the progression of damage variables in the elements and considering crack propagation as additional elements being fully damaged. However, the KST model is still used to describe the compressive response of such elements meaning that the structural cracks should be considered as closed and that they can still carry compressive loading.

The present approach to modeling structural cracks is straightforward and fairly simple but can be justified for mainly two reasons. First of all, in order to model the effect of structural cracks, a large number of such defects must be included in the analysis. It then requires very large numerical efforts if all such cracks are modeled as sharp open cracks including possible contact between crack faces. This is particularly so as in the applications in the succeeding texts, EOI testing and percussive drilling, mainly mode I cracking is at issue and this is very accurately modeled by the present approach. The latter feature has been extensively investigated and verified by presently performed numerical experiments. Secondly, most of the microscopically observed structural (or pre-existing) cracks are indeed closed, and it is then from a mechanical point of view a good approximation to model the compressive behavior (including shearing effects) using the KST model. In summary then, it is believed that the approach used here to model the structural cracks as basically pre-damaged regions is sufficiently accurate for the present analysis.

\section{EOI TEST WITH STRUCTURAL CRACKS}

In order to validate the numerical model and also to investigate the fracture pattern after impact, EOI tests with the sarcophagus configuration and its confining system have been performed in a previous study [18]. As indicated in ref. [18], the results from the EOI tests on granite were not completely satisfactory (as expected) and the number of large cracks was rather small (refer to Figure 1). This was explained by the presence of pre-existing cracks in the specimens, most likely introduced during the sample preparation. A preliminary analysis with structural cracks has been performed showing a slightly better agreement between experiments and simulations in terms of cracking density and failure pattern.

However, the original KST-DFH model predicts higher numbers of large cracks than observed in the experiments (refer to Figure 2). This inconsistency occurs as the intact material without



a)

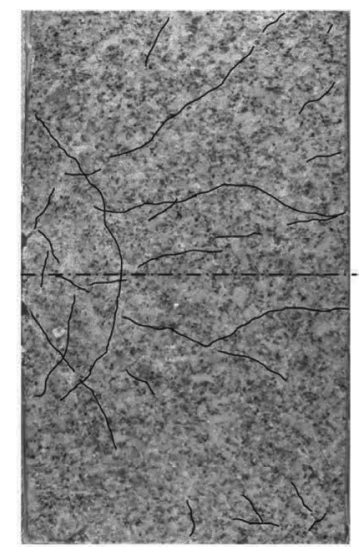

b)

Figure 1. EOI test of granite specimen impacted by an aluminum projectile whose velocity is equal to $150 \mathrm{~m} / \mathrm{s}$ (a); damage pattern is marked to be observable after the experiment (b). 


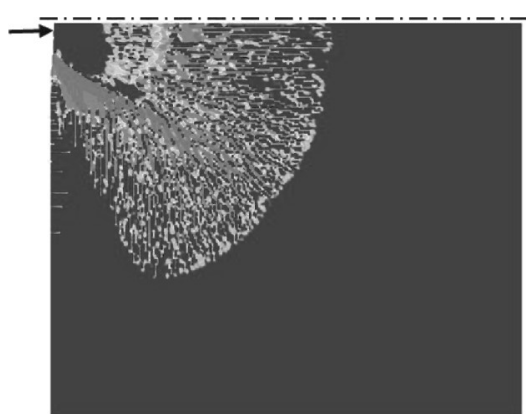

a)

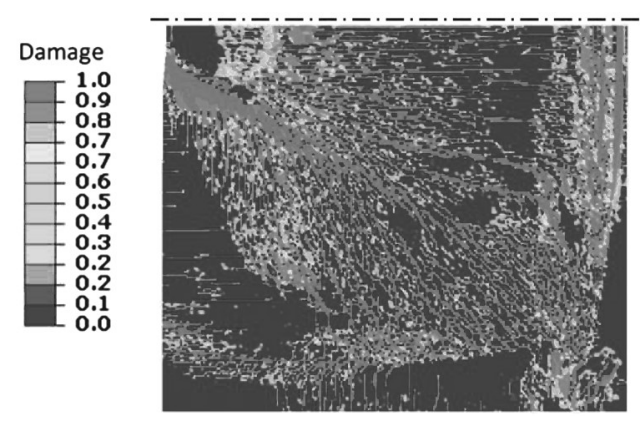

b)

Figure 2. FE simulation results of the EOI test shown in Figure 1. Damage variable $D_{1} 20 \mu \mathrm{s}$ (a) and $40 \mu \mathrm{s}$ (b) after impact (impact velocity: $150 \mathrm{~m} / \mathrm{s}$ ).

structural cracks has a low scatter in the defect size and distribution, which corresponds to a rather large Weibull modulus in the model. The multiple fragmentation process then includes the activation of a large number of material defects at the same time as they are in the same size range. Consequently, a significant number of large cracks are formed according to the numerical results.

The pre-existing cracks with different length and orientation are introduced according to the approach discussed in the preceding texts, and the results are compared with the experiments. A quarter-symmetry 3D FE model of the EOI tests with all modeling details, such as mesh design and contact method, similar to what was formerly reported by the authors [18], is performed in this investigation (refer to Figure 3). It can be concluded from the numerical results that the difference in the fracture pattern is not significant when changing the crack lengths and orientations. Figure 4 shows a uniform distribution of evenly $1 \mathrm{~cm}$ long structural cracks, which is of the same order of size as the largest grains in the material in the specimen. The effective stiffness of the specimen drops from 52 to $44.5 \mathrm{GPa}$ because of these pre-existing structural cracks (this is obtained from the numerical simulation of uniaxial loading of the specimen at quasi-static condition).

The maximum damage variable distribution at different times after impact is shown in Figure 5. It can be seen that the number of large cracks decreases considerably and the results are much closer to the experimental observations. The cracks are mainly initiated from the existing crack tips, and in some cases, the cracks coalesce. The stress state around the cracks does not increase considerably, indicating that the material in this region is shielded from fracturing. It should be mentioned that these results are more realistic than the preliminary simulation results with structural cracks [18]. In ref. [18], the specimen was first impacted with a striker velocity of $20 \mathrm{~m} / \mathrm{s}$ in a numerical simulation in order to produce an initial damage state. The specimen was subsequently impacted at $150 \mathrm{~m} / \mathrm{s}$ (similarly to the experiment).

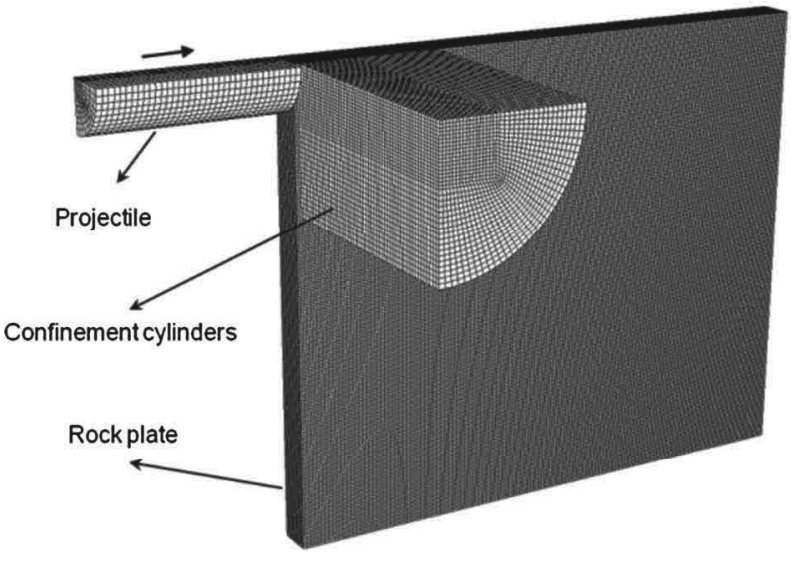

Figure 3. FE mesh used in the simulations of the EOI test. Quarter-symmetry model with 775,000 8-noded linear elements. 


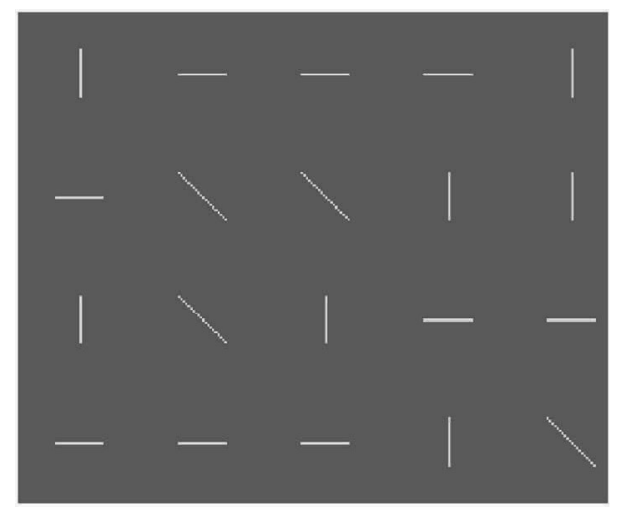

Figure 4. Random distribution of evenly sized $1 \mathrm{~cm}$ long pre-existing cracks in the specimen (the cracks depth is the same as the specimen thickness).

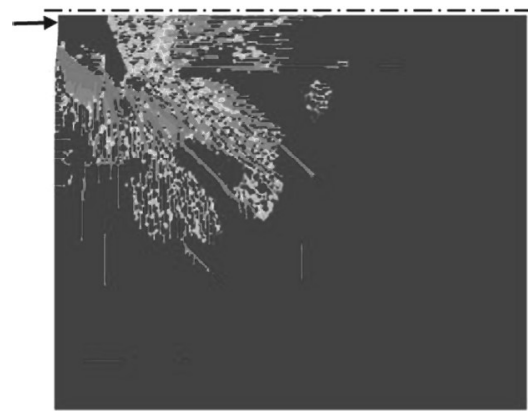

a)

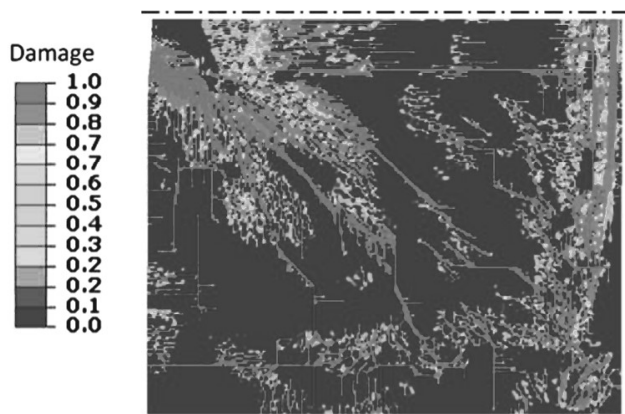

b)

Figure 5. FE simulation results of the EOI test with a random orientation of $1 \mathrm{~cm}$ long pre-existing cracks. Damage variable $D_{1} 20 \mu \mathrm{s}$ (a) and $40 \mu \mathrm{s}$ (b) after impact (velocity: $150 \mathrm{~m} / \mathrm{s}$ ).

The reflection of the compressive wave from the free surface of the specimen in the EOI test has a considerable effect on the cracking behavior. This is obvious from both the experimental and numerical results as the crack density is higher close to the free surface as a result of the reflected tensile wave, refer to Figures 1 and 2. However, the reflection of the compressive wave from the pre-existing cracks has a less significant as shown in Figure 5.

\section{MODELING OF PERCUSSIVE DRILLING WITH STRUCTURAL CRACKS}

The effect of the pre-existing cracks on the percussive drilling problem is numerically investigated in this section. It should be noted that it is always a possibility that these cracks are present in a real drilling situation, because of previous impact from the drill tool for instance. In addition, this study may be beneficial in order to determine the effect of the pre-existing cracks when they are deliberately introduced using methods such as microwave and laser loadings to facilitate the percussive drilling process. The results can partly answer the related questions about the optimum length and orientation of these cracks facilitating the extraction of the material at drilling.

Different cases with respect to crack orientations are investigated, and the results are compared. The two main features in this comparison are penetration stiffness and fracture pattern. The former one corresponds to the required force, $P_{b}$, for reaching a certain penetration depth, $h$, and the latter gives an indication of the fragmentation process and the material chip size and shape. A quarter-symmetry 3D FE analysis of percussive drilling with all modeling details, such as mesh design and contact method, similar to what has previously been reported [18], is performed hereafter. A quartersymmetry analysis is performed as a complete 3D FE analysis, in particular with contact modeling, 
and is very numerically expensive. However, the heterogeneity of the material is taken into account in each quarter-symmetry part. This is performed by using Weibull statistic and allocating a random tensile strength to each element accordingly.

The incident stress pulse has a level of $200 \mathrm{MPa}$ with duration of $2 \times 10^{-4} \mathrm{~s}$ and with a rising and descending time of $10^{-5} \mathrm{~s}$. A hemispherical indenter $(5 \mathrm{~mm}$ in radius) is chosen. The steel drill rod is $1 \mathrm{~m}$ in length and $6 \mathrm{~mm}$ in radius. In a real tool, the drill rod cross-sectional area is a bit larger than the sum of the cross-sectional areas of all buttons. Accordingly, the drill rod radius is taken a bit larger than the button in order to take into account the geometric impedance difference between them. Both the drill rod and the button are assumed to be elastically deformable with elastic moduli equal to 200 and $800 \mathrm{GPa}$ respectively. A block of rock with a size of $200 \times 200 \times 100 \mathrm{~mm}^{3}$ is exposed to impact. The FE mesh used in the simulation is shown in Figure 6 using 8-node linear elements with reduced integration. Infinite elements are used at the rock boundaries to eliminate the wave reflection.

Three categories of crack orientation, namely horizontal, vertical and combined with respect to the rock-tool contact surface, are shown in Figure 7. The length of the cracks is chosen to be $2 \mathrm{~mm}$ in this case (i.e. of the same order of magnitude as small grain sizes in the material), and the corresponding depth is equal to $0.25 \mathrm{~mm}$, but other crack lengths will be considered in the succeeding texts. These cracks consist of sets of elements with negligible allocated tensile strength that leads to their immediate failure when loaded in tension. They can, however, still carry compressive load as explained in the preceding texts.

First, according to Figure 8, the pre-existing cracks reduce the penetration stiffness (i.e. the slope of the $P_{b}-h$ curve during loading) in all cases, which means that a smaller load is required in order to reach a certain penetration depth. The penetration stiffness drops from $340 \mathrm{kN} / \mathrm{mm}$ (for the crackfree situation) to 321,318 and $308 \mathrm{kN} / \mathrm{mm}$ for horizontal, vertical and combined orientations, respectively. The reduction in the penetration stiffness is higher in the case of combined orientation as the number of cracks is higher in this last case. If a single crack is added beneath the indenter close to the free surface in the horizontal orientation (Figure 9), a significant reduction in the penetration stiffness is observed as this quantity drops down to $254 \mathrm{kN} / \mathrm{mm}$. This most likely corresponds to the shearing and distortion of the newly added crack elements, and consequently, a larger penetration is obtained. Physically, a horizontal crack beneath the indenter and close to the

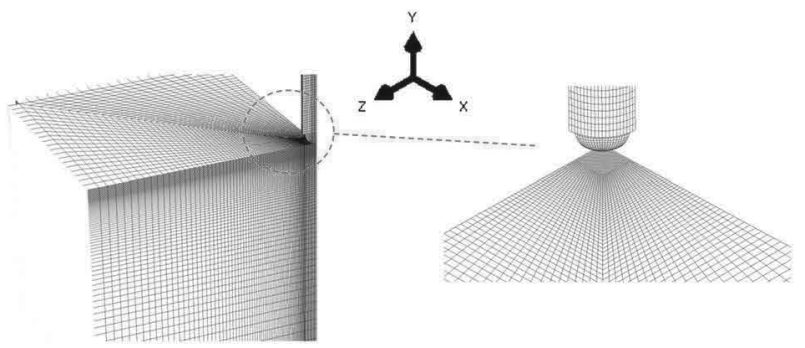

Figure 6. FE mesh used in the simulations of percussive drilling. Because of symmetries, only a quarter of the problem is modeled with 400,000 8-noded elements.

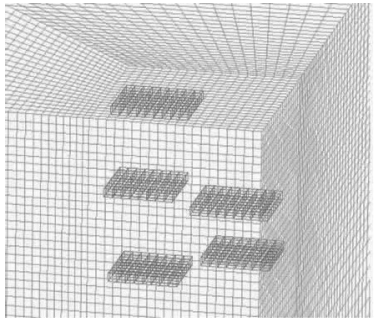

a)

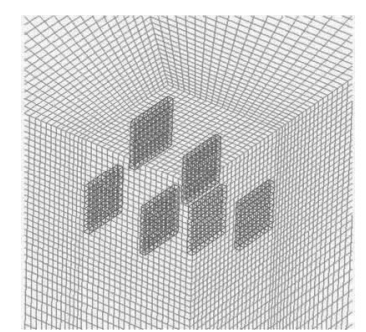

b)

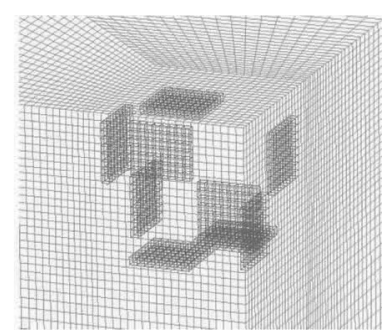

c)

Figure 7. Views of different orientations of pre-existing cracks $(2 \mathrm{~mm}$ in length) in the rock beneath the drilling tool. Horizontal (a), vertical (b) and combined (c) crack orientations. 


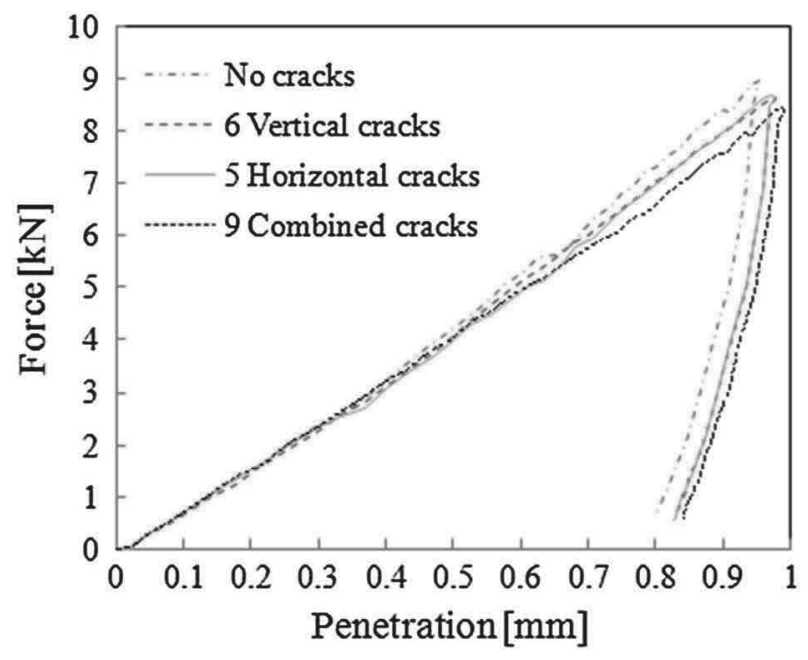

Figure 8. FE simulation results of percussive drilling. Force-penetration $\left(P_{b}-h\right)$ curves of the drill bit for different initial crack patterns (refer to Figure 7).



Figure 9. Location of pre-existing cracks ( $2 \mathrm{~mm}$ in length) as shown in Figure 7(a) with one additional crack beneath the drilling tool close to the free surface.

free surface facilitates the material flow in the radial direction and leads to an easier penetration. This is in some respect similar to the situation associated with scratching of delaminated thin coatings [26, 27].

A typical fracture pattern in a rock material as a result of quasi-static indentation has been determined by Tan et al. [1]. It includes different types of cracks and also a high compressive part under the indenter called the crushed zone, refer to Figure 10. Similar types of cracks are captured from the numerical results corresponding to a dynamically loaded drilling tool [18].

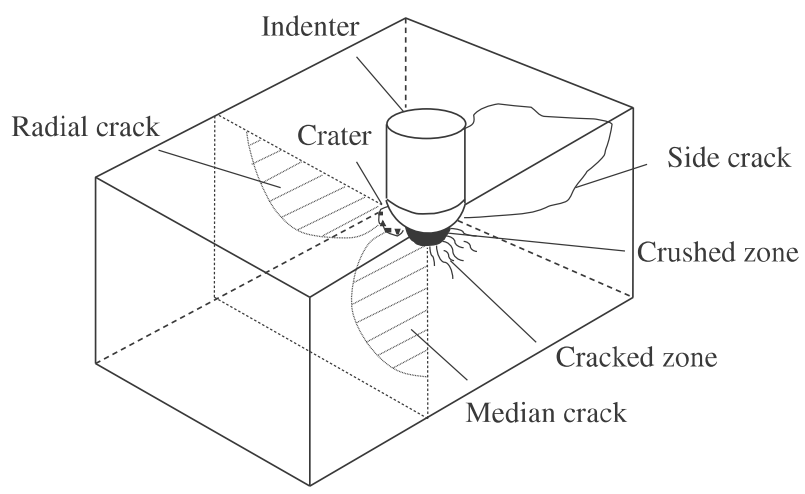

Figure 10. Cracking pattern in rocks at quasi-static indentation [1]. 
Selected simulation results for the damage variable, induced by the maximum tensile principal stress, are shown in Figure 11. The fracture patterns in all three cases with pre-existing cracks shown in Figure 7 and also the case without any pre-existing cracks are compared at the end of the loading and unloading steps in Figure 11. The lengths of the radial and median cracks are in the same range in all cases with different pre-existing crack orientations and the original model without

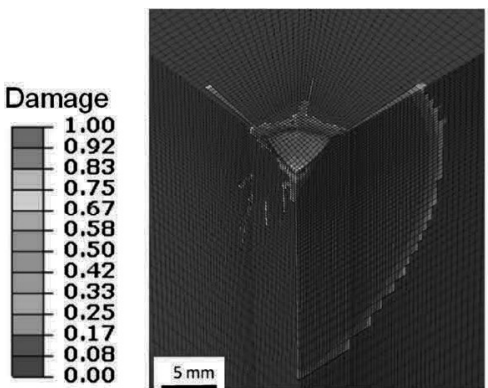

a)

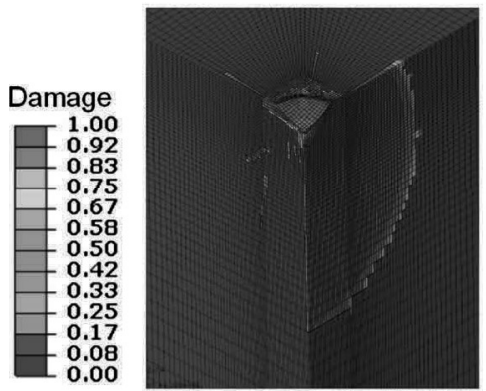

c)

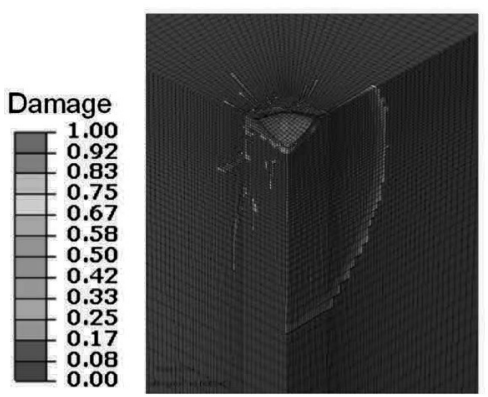

e)

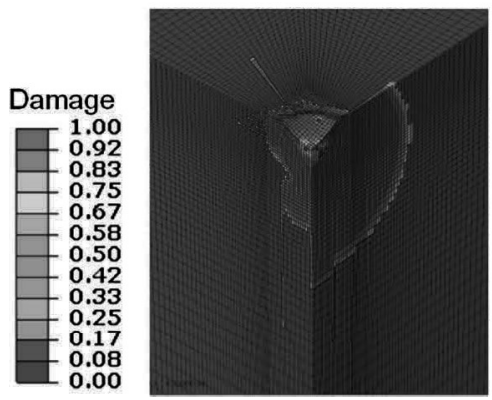

g)

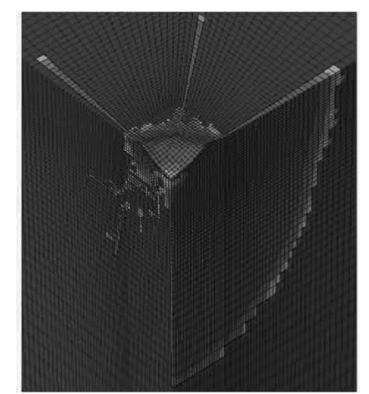

b)

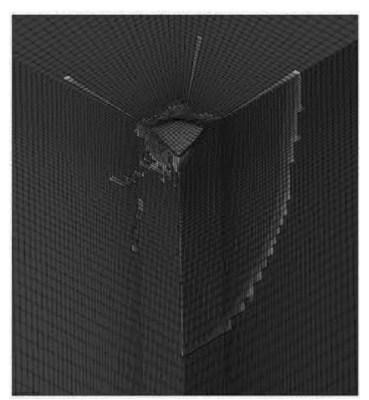

d)

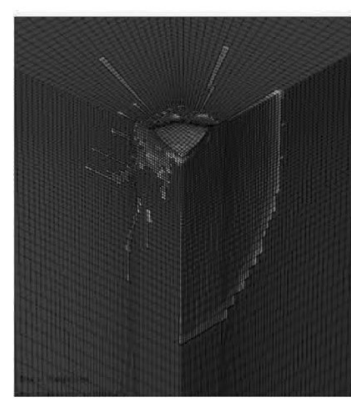

f)

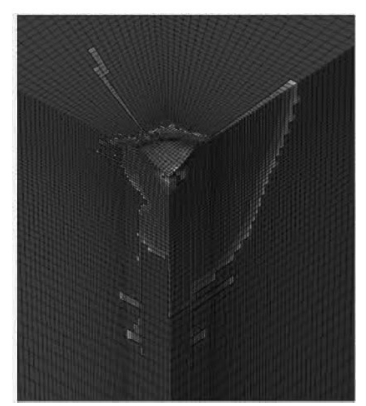

h)

Figure 11. FE simulation results (damage variable $D_{1}$ ) of percussive drilling with and without pre-existing cracks in different orientations shown in Figure 7. No cracks, at the end of loading (a) and at the end of unloading (b). Horizontal cracks, at the end of loading (c) and at the end of unloading (d). Vertical cracks, at the end of loading (e) and at the end of unloading (f). Combined cracks, at the end of loading (g) and at the end of unloading $(\mathrm{h})$ 
structural cracks, with the exception that they are slightly shorter in the case of vertical cracks. Side cracks are mainly created during unloading, similar to the situation discussed in ref. [18]. In the simulations with a horizontal orientation of pre-existing cracks, the side cracks are slightly shorter than those in the other cases. Otherwise, no significant difference is found concerning the initiation of side cracks between the different pre-existing crack orientations considered in this investigation. In this context, it should also be mentioned that the other two damage variables (corresponding to the intermediate and minimum tensile principal stress) in the KST-DFH material model are also activated and grow during the simulations.

Underneath the tool, at and close to the contact region, high compressive hydrostatic stresses are formed. This will lead to very high values on the effective plastic strain corresponding to the formation of the crushed zone discussed in the preceding texts.

The propagation of existing cracks is, as opposed to the formation and growth of newly created cracks, the dominating fracture feature. This facilitates the multiple fragmentations as these cracks are believed to coalesce with existing or newly initiated cracks in a much shorter time. Consequently, the introduction of pre-existing cracks most likely leads to extracting larger chips of material during the drilling process. Furthermore, cracks of length $5 \mathrm{~mm}$ are introduced with different orientations. As the radius of the indenter is also $5 \mathrm{~mm}$ in the simulations, only three of these cracks are introduced in the region beneath the indenter. The penetration stiffness decreases considerably compared with the cases with 2-mm-long cracks and reaches levels of 282 and $248 \mathrm{kN} / \mathrm{mm}$ for horizontal and vertical crack orientations, respectively. Regarding the fracture pattern, the same conclusions as those concerning 2-mm-long cracks are still valid. It should be mentioned that the fracture pattern from the numerical simulations is not symmetric. This is because the elements have a random tensile strength, and accordingly, the problem is not completely symmetric.

From the previous discussion about the penetration stiffness and the fracture pattern, it is shown that introducing pre-existing cracks in the rock prior to regular percussive drilling is beneficial from an efficiency point of view (lower penetration stiffness and larger chips of extracted material). However, as different crack orientations do not show a significant difference concerning the fracture pattern beneath the tool and also considering the practical challenges of producing cracks in a specific orientation, the pre-existing random crack pattern is sufficient for this purpose. Increasing the length of the vertical cracks facilitates more the penetration and has a considerable effect on penetration stiffness while the length of horizontal cracks has a smaller influence on this quantity.

\section{CONCLUSIONS}

The effect of pre-existing or structural cracks on the dynamic fragmentation of granite is investigated in this study. The KST-DFH material model [10] is used for this purpose, and the material parameters are calibrated for Bohus granite by a set of previously performed experiments [19]. The numerical simulations have been performed using a VUMAT subroutine implemented in the commercial FE code Abaqus Explicit [25].

The fracture pattern after impact is investigated when pre-existing cracks are present in the material. The pre-existing cracks are introduced in the model by considering sets of elements with negligible tensile strength that leads to their immediate failure when loaded in tension. They can still carry compressive loads when crack closure occurs because of compressive stresses.

EOI tests, which were previously performed [18], are reconsidered here to validate the numerical model. The pre-existing cracks with different lengths and orientations are introduced in the numerical simulation, and it is shown that their presence changes the fracture pattern. The number of large cracks decreases considerably, and the numerical results are in a better agreement with the experimental ones. However, there is no significant difference in the fracture pattern when changing the crack lengths and orientation.

Percussive drilling is simulated with the presently developed numerical tool, and the influence from the pre-existing cracks is studied. These cracks can be introduced in the rock during drilling because of either former impact of the drill bit using methods such as microwave and laser loadings to facilitate the percussive drilling process. The results from different analyses are compared in terms of penetration 
stiffness and fracture pattern. It is shown that pre-existing cracks facilitate in all cases the drilling process regardless of their orientation. Different pre-existing crack orientations do not have a significant influence on the fracture pattern beneath the tool, and also, considering the practical challenges of creating cracks in a specific orientation, pre-existing cracks with a random pattern are sufficient for this purpose. Increasing the length of pre-existing cracks facilitates the penetration and has a considerable effect on the penetration stiffness. Furthermore, introducing horizontal cracks beneath the indenter and close to the free surface significantly decreases the penetration stiffness.

\section{REFERENCES}

1. Tan XC, Kou SQ, Lindqvist P-A. Application of the DDM and fracture mechanics model on the simulation of rock breakage by mechanical tools. Engineering Geology 1998; 49(3-4):277-284.

2. Jaeger JC, Cook NGW, Zimmerman R. Fundamentals of rock mechanics. Wiley-Blackwell: Malden, 2007.

3. Liu HY, Kou SQ, Lindqvist P-A, Tang CA. Numerical simulation of the rock fragmentation process induced by indenters. International Journal of Rock Mechanics and Mining Sciences 2002; 39(4):491-505.

4. Wang SY, Sloan SW, Liu HY, Tang CA. Numerical simulation of the rock fragmentation process induced by two drill bits subjected to static and dynamic (impact) loading. Rock Mechanics and Rock Engineering 2011; 44(3):317-332.

5. Saksala T. Damage-viscoplastic consistency model with a parabolic cap for rocks with brittle and ductile behavior under low-velocity impact loading. International Journal for Numerical and Analytical Methods in Geomechanics 2010; 34(13):1362-1386.

6. Saksala T. Numerical modelling of bit-rock fracture mechanisms in percussive drilling with a continuum approach. International Journal for Numerical and Analytical Methods in Geomechanics 2011; 35(13):1483-1505.

7. Saksala T. 3D numerical modelling of bit-rock fracture mechanisms in percussive drilling with a multiple-button bit. International Journal for Numerical and Analytical Methods in Geomechanics 2013; 37(3):309-324.

8. Chiang LE, Elias DA. A 3D FEM methodology for simulating the impact in rock-drilling hammers. International Journal of Rock Mechanics and Mining Sciences 2008; 45(5):701-711.

9. Thuro K, Schormair N. Fracture propagation in anisotropic rock during drilling and cutting. Geomechanics and Tunnelling 2008; 1(1):8-17.

10. Forquin P, Hild F. A Probabilistic Damage Model of the Dynamic Fragmentation Process in Brittle Materials. Advances in Applied Mechanics 2010; 44:1-72.

11. Krieg RD. A simple constitutive description for soils and crushable foams. Report, SC-DR-7260883, Sandia Natl. Lab., 1978 .

12. Swenson DV, Taylor LM. A finite element model for the analysis of tailored pulse stimulation of boreholes. International Journal for Numerical and Analytical Methods in Geomechanics 1983; 7(4):469-484.

13. Denoual C, Hild F. A damage model for the dynamic fragmentation of brittle solids. Computer Methods in Applied Mechanics and Engineering 2000; 183(3):247-258.

14. Grange S, Forquin P, Mencacci S, Hild F. On the dynamic fragmentation of two limestones using edge-on impact tests. International Journal of Impact Engineering 2008; 35(9):977-991.

15. Forquin P, Erzar B. Dynamic fragmentation process in concrete under impact and spalling tests. International Journal of Fracture 2010; 163(1-2):193-215.

16. Erzar B, Forquin P. An experimental method to determine the tensile strength of concrete at high rates of strain. Experimental Mechanics 2010; 50(7):941-955.

17. Erzar B, Forquin P. Experiments and mesoscopic modelling of dynamic testing of concrete. Mechanics of Materials 2011; 43(9):505-527.

18. Saadati M, Forquin P, Weddfelt K, Larsson PL, Hild F. Granite rock fragmentation at percussive drilling experimental and numerical investigation. International Journal for Numerical and Analytical Methods in Geomechanics 2014; 38(8):828-843.

19. Saadati M, Forquin P, Weddfelt K, Larsson PL, Hild F. On the mechanical behavior of granite material with particular emphasis on the influence from pre-existing cracks and defects. Report, Department of Solid Mechanics, Royal Institute of Technology (KTH), Stockholm, Sweden, 2013. Submitted for international publication.

20. Weibull W. A Statistical Theory of the Strength of Materials. Report 151, Royal Institute of Technology, Stockholm, 1939.

21. Weibull W. A statistical distribution function of wide applicability. Journal of Applied Mechanics 1951; 18(3):293-297.

22. Davies DGS. The statistical approach to engineering design in ceramics. Proceedings of the British Ceramic Society 1973; 22(6):429-452.

23. Erzar B, Forquin P. Analysis and modelling of the cohesion strength of concrete at high strain-rates. International Journal of Solids and Structures 2014; 51(14):2559-2574.

24. Sallier L, Forquin P. Influence of the Confined Behaviour and the Tensile Strength of Concrete Slabs Under Projectile-Impact. In Dynamic Behavior of Materials, Volume 1, Springer: New York, 2013: 567-571.

25. Abaqus 6.11. Dassault Systèmes Simulia Corp.: Providence, RI, USA, 2011.

26. Wredenberg F, Larsson P-L. Scratch testing of metals and polymers: experiments and numerics. Wear 2009; 266(1):76-83.

27. Wredenberg F, Larsson P-L. Delamination of thin coatings at scratching: experiments and numerics. Journal of Mechanics of Materials and Structures 2009; 4(6):1041-1062. 